\title{
Supporting information to the article
}

\section{Dual Temperature Responsive Microgel from a}

\section{Zwitterionic Functional Graft Copolymer with}

\section{Superior Protein Repelling Property}

Pabitra Saha, ${ }^{1,2}$ Marta Santi, ${ }^{1,2}$ Martin Frenken, ${ }^{1}$ Anand Raj Palanisamy, ${ }^{4}$ Ritabrata Ganguly, ${ }^{4}$ Nikhil K. Singha, ${ }^{4, *}$ Andrij Pich ${ }^{1,2,3,{ }^{*}}$

${ }^{1}$ DWI - Leibniz-Institute for Interactive Materials, Aachen, Germany

${ }^{2}$ Institute of Technical and Macromolecular Chemistry, RWTH Aachen University, Germany

${ }^{3}$ Aachen Maastricht Institute for Biobased Materials (AMIBM), Maastricht University, the Netherlands

${ }^{4}$ Rubber Technology Centre, Indian Institute of Technology Kharagpur, India

Materials. The RAFT agent methyl 2-(ethoxycarbonothioylthio) propanoate (MECP) was synthesized as reported by Peng et al. 4,4'-Azobis(4-cyanovaleric acid) (ABCVA, 98\%), azobisisobutyronitrile $\quad$ (AIBN, $\quad 98 \%), \quad$ [2-(Methacryloyloxy)ethyl]dimethyl-(3sulfopropyl)ammonium hydroxide (SB, 99.5\%), 4-Cyano-4-(phenylcarbonothioylthio)pentanoic 
acid (CPCPA, 98\%), glycidyl methacrylate (GMA, 97\%), $N$ - vinylcaprolactam (VCL, 98\%), sodium borohydrate $\left(\mathrm{NaBH}_{4}, 96 \%\right)$, anisole $(99.7 \%)$, toluene $(99.7 \%)$ were obtained from Sigma Aldrich. Crosslinker 1,6- hexadiamine (99.5\%), Acetone (100\%) were purchased from ACROS organics and VWR respectively. GMA was distilled to remove the inhibitor by passing through a standard alumina column and VCL was distilled followed by recrystallization from hexane before use. The regenerated cellulose membranes, obtained from Carl Roth were washed with deionized water prior to usage. For all experiments deionized water was used whenever it was required.

\section{Synthesis of methyl 2-(ethoxycarbonothioylthio) propanoate (MECP) RAFT agent. A} solution of methyl 2-bromopropionate (2 $\mathrm{g}, 11.7 \mathrm{mmol}, 1$ eq. $)$ in ethanol $(15 \mathrm{~mL})$ was stirred in a double-neck flask immersed in an ice bath. Potassium ethyl xanthogenate $(2.16 \mathrm{~g}, 13.4 \mathrm{mmol}, 1.1$ eq.) was progressively added with a spatula for $45 \mathrm{~min}$. The solution became yellowish. After addition, the solution was mixed for $3 \mathrm{~h}$ at room temperature. The formation of potassium bromide (insoluble in ethanol) was observed. The solution was then filtered with a Buchner funnel and concentrated under reduced pressure with a rotary evaporator. Dichloromethane $(30 \mathrm{~mL})$ was then added and the product was extracted in the organic phase after treatment with distilled water $(4 \times$ $50 \mathrm{~mL})$. The organic phase was dried over magnesium sulphate $\left(\mathrm{MgSO}_{4}\right)$ overnight in an Erlenmeyer flask. After filtration, dichloromethane was removed in a rotary evaporator. The product was dried under vacuum to obtain a yellow bright liquid (2.09 g, yield 91.1\%). See Figure S 1: ${ }^{1} \mathrm{H}$ NMR (in $\left.\mathrm{CDCl} 3\right): \delta[\mathrm{ppm}]=4.56\left(-\mathrm{OCH}_{2} \mathrm{CH} 3\right), 4.32\left(\mathrm{CHCH}_{3}\right), 3.69\left(-\mathrm{OCH}_{3}\right), 1.52$ $\left(\mathrm{CHCH}_{3}\right), 1.35\left(-\mathrm{OCH}_{2} \mathrm{CH}_{3}\right)$. 


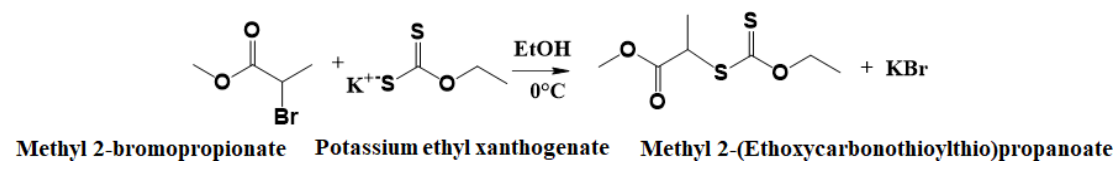

Scheme S 1. Synthesis outline of methyl 2-(ethoxycarbonothioylthio) propanoate (MECP)

RAFT agent

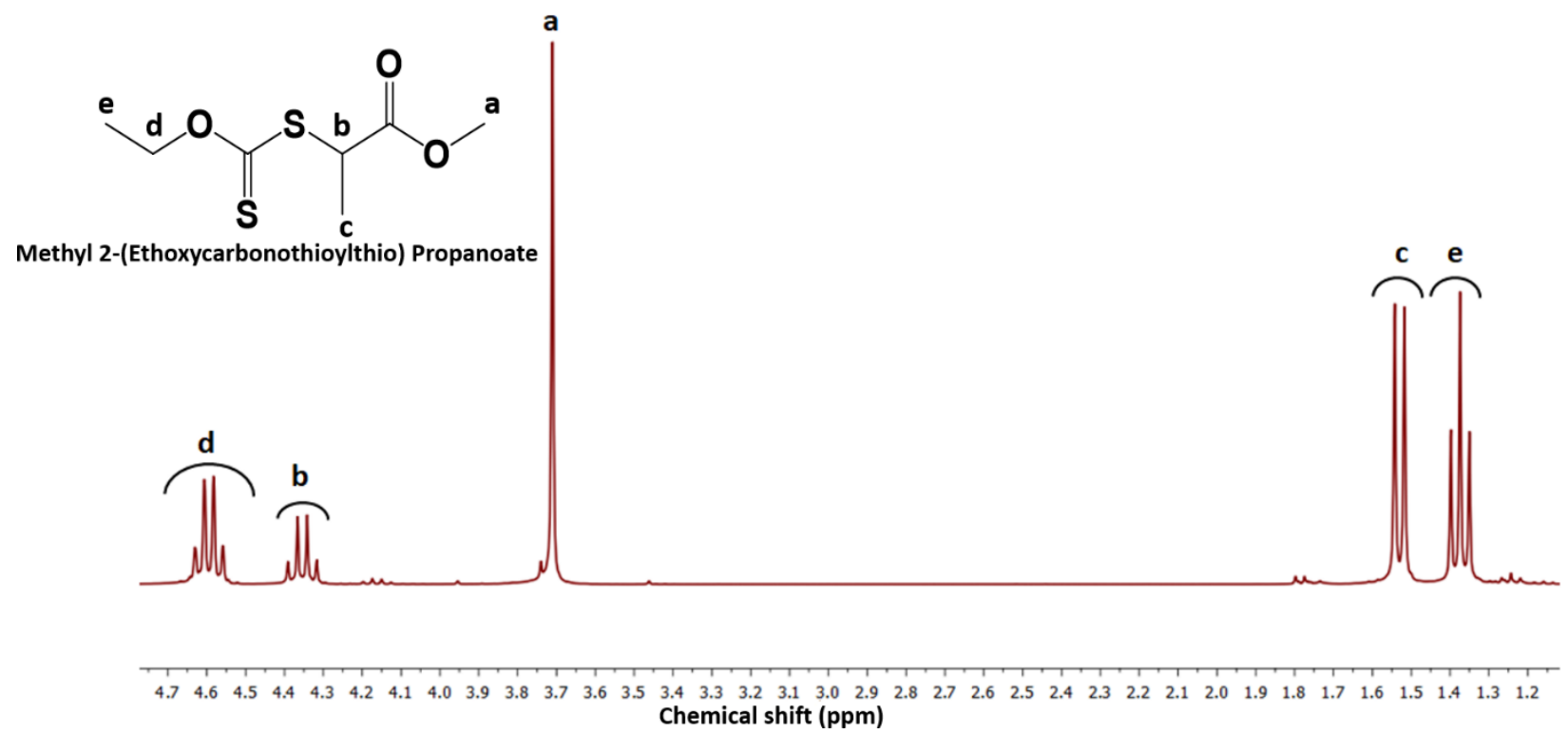

Figure S 1. ${ }^{1} \mathrm{H}$ NMR spectrum of methyl 2-(ethoxycarbonothioylthio) propanoate (MECP)

RAFT agent

Synthesis of PVCL-co-PGMA random copolymer. To obtain a random copolymer with a molecular weight of 5000, VCL with the RAFT-agent MECP, GMA and the initiator AIBN were separately dissolved in anisole and purged with nitrogen to remove oxygen from the system for 30 min. The VCL and MECP solution was heated to $65^{\circ} \mathrm{C}$ and the AIBN was added. The GMA solution was added continuously at a fixed flow rate with a syringe pump (Harvard apparatus) over $7 \mathrm{~h}$ (see Scheme S 2). The reaction was stopped by exposure to normal atmosphere after $30 \mathrm{~h}$ and cooled down under ice cold water. The mixture was precipitated in a large volume of ice-cold diethyl ether and washed several times with the same solvent followed by filtration. The residual 
white mass was dried under reduced pressure over night at $40{ }^{\circ} \mathrm{C}$ to obtain $55-60 \%$ yield. The details of the reaction are discussed in Table $\mathbf{S} \mathbf{1}$.

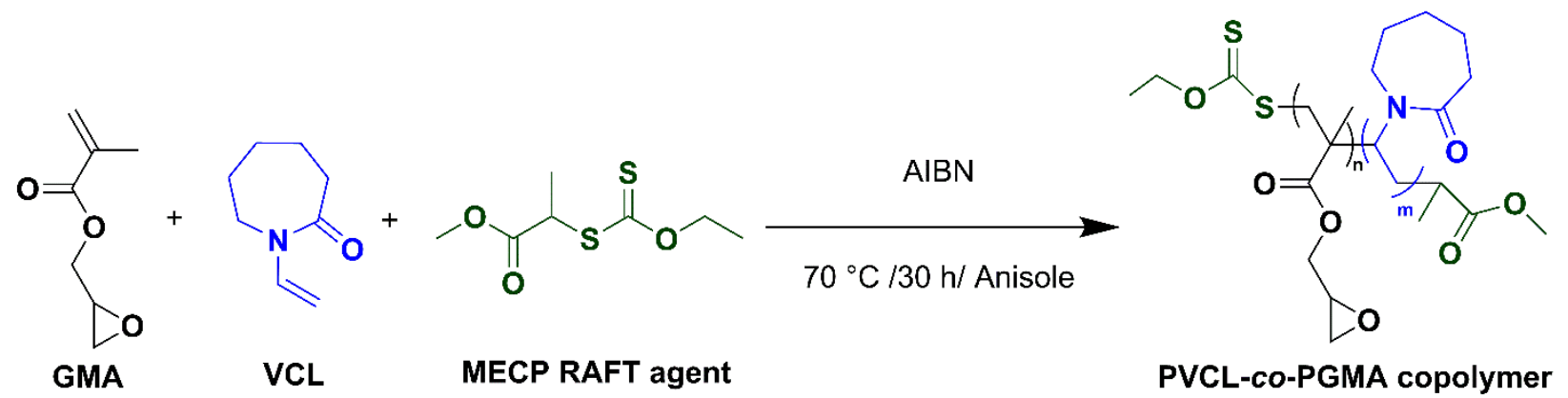

Scheme S 2. Synthesis outline of PVCL-co-PGMA copolymer

Table S 1. Molar composition of PVCL-co-PGMA copolymer synthesis

\begin{tabular}{|c|c|c|c|c|c|c|c|c|c|c|}
\hline Sample & $\begin{array}{c}\text { Theoretical } \\
\text { GMA } \\
\text { content } \\
(\text { mol\%) }\end{array}$ & $\begin{array}{l}\text { VCL } \\
(\mathrm{g})\end{array}$ & $\begin{array}{c}\text { MECP } \\
\text { RAFT } \\
\text { (g) }\end{array}$ & $\begin{array}{l}\text { Anisole } \\
(\mathrm{mL})\end{array}$ & $\begin{array}{c}\text { GMA } \\
(\mathrm{g})\end{array}$ & $\begin{array}{l}\text { Anisole } \\
(\mathrm{mL})\end{array}$ & $\begin{array}{c}\mathrm{AIBN} \\
(\mathrm{mg})\end{array}$ & $\begin{array}{l}\text { Anisole } \\
(\mathbf{m L})\end{array}$ & $\begin{array}{c}\text { Molecular } \\
\text { weight } \\
\text { from } \\
\text { GPC, } \\
\text { Mn,GPC }^{\text {s }} \\
\end{array}$ & $\begin{array}{l}\text { PDI } \\
\text { (Đ) }\end{array}$ \\
\hline $\mathrm{PVG}_{15}$ & 15 & 1.000 & 0.025 & 2 & 0.180 & 1 & 6 & 0.5 & -- & -- \\
\hline $\mathrm{PVG}_{10}$ & 10 & 1.000 & 0.024 & 2 & 0.113 & 1 & 6 & 0.5 & 4313 & 1.16 \\
\hline $\mathrm{PVG}_{5}$ & 5 & 1.000 & 0.022 & 2 & 0.154 & 1 & 6 & 0.5 & 4754 & 1.23 \\
\hline \multicolumn{11}{|c|}{$\begin{array}{l}\mathrm{M}_{\mathrm{n}, \mathrm{GPC}}{ }^{\$} \text { : The } \mathrm{PVG}_{15} \text { sample with } 15 \mathrm{~mol} \% \text { GMA was insoluble in water, so it was not used for } \\
\text { this work and GPC experiment was not done with this sample }\end{array}$} \\
\hline \multicolumn{11}{|c|}{ The GPC traces of PVCL-co-PGMA random copolymer prepared with 5 and $10 \mathrm{~mol} \% \mathrm{GMA}$} \\
\hline \multicolumn{11}{|c|}{ content are given in the Figure $\mathbf{S} \mathbf{2}$, which represents unimodal distribution with very low } \\
\hline \multicolumn{11}{|c|}{ polydispersity index $(Đ)$, suggesting a good control over the molecular weight during RAFT } \\
\hline
\end{tabular}




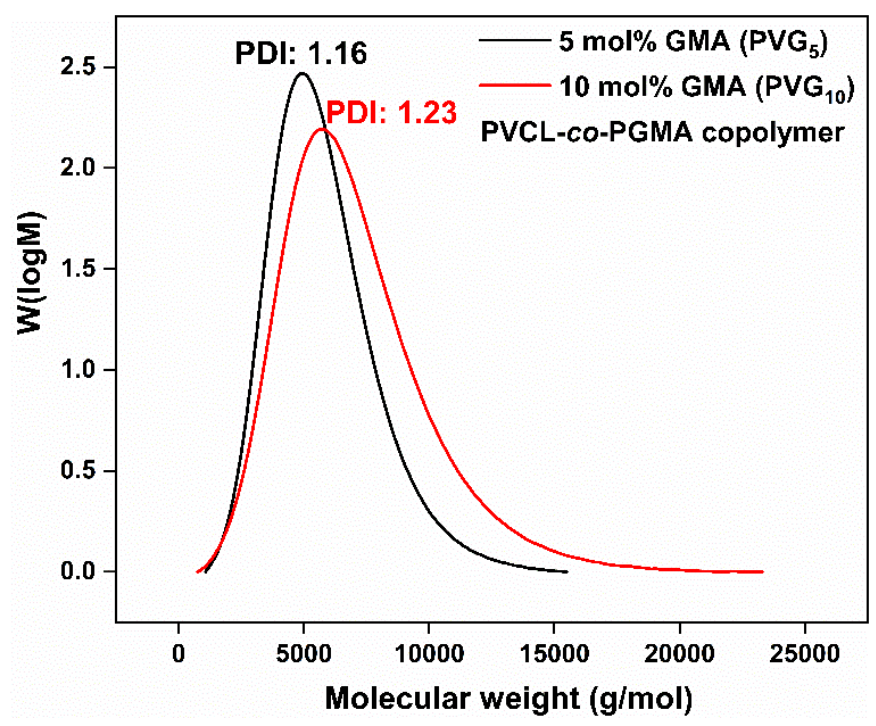

Figure S 2. GPC traces of PVCL-co-PGMA copolymers $\left(\mathrm{VG}_{5}\right.$ with $5 \mathrm{~mol} \% \mathrm{GMA}$ and $\mathrm{VG}_{10}$ with 10 mol\% GMA)

The PVCL-co-PGMA random copolymers were characterized by ${ }^{1} \mathrm{H}$ NMR and FTIR, which are discussed here (see Figure S 3 and Figure S 4 respectively). 


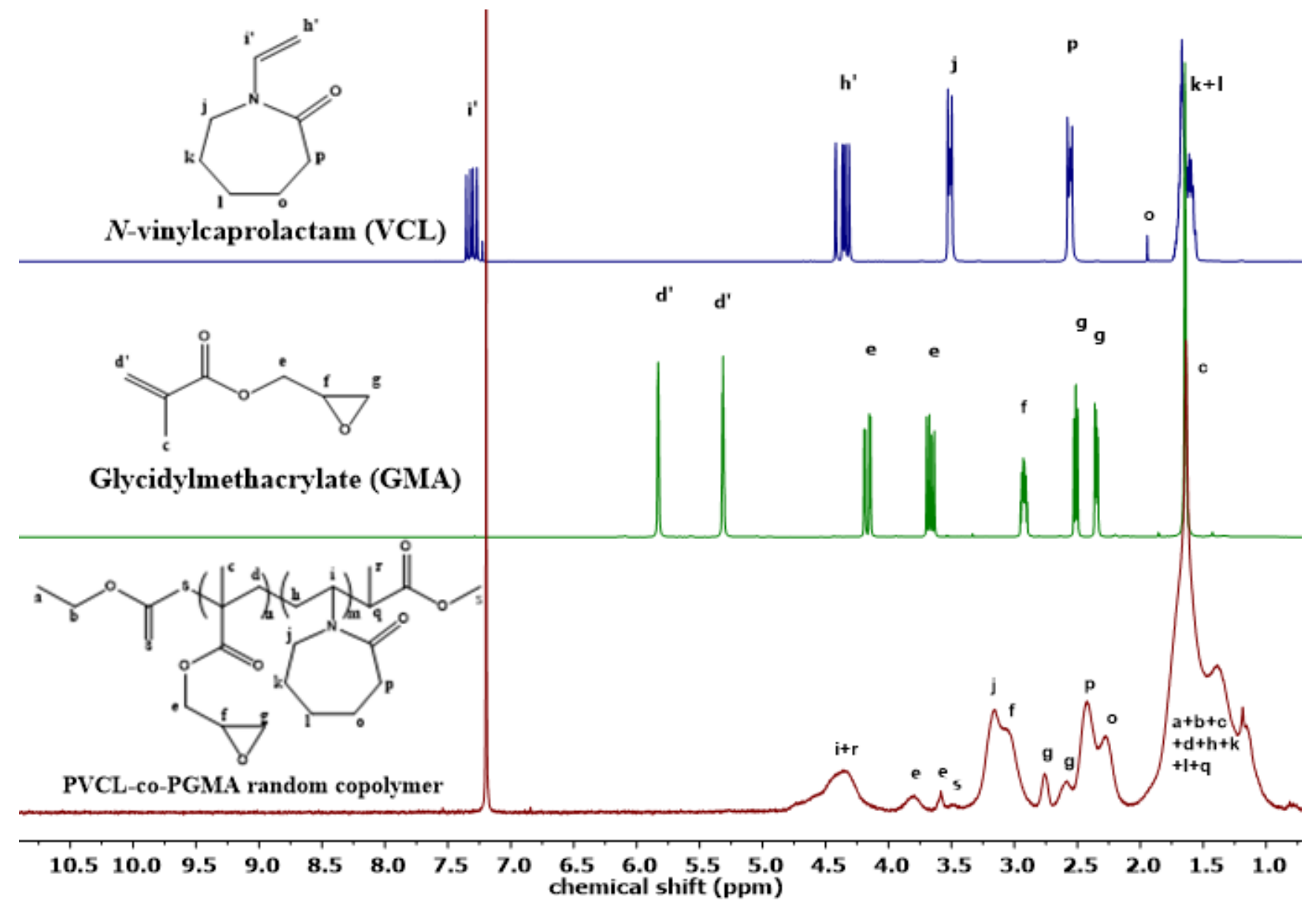

Figure S 3. ${ }^{1} \mathrm{H}$ NMR spectra of VCL monomer, GMA monomer and PVCL-co-PGMA (PVG5 with 5 mol\% GMA) random copolymer in $\mathrm{CDCl}_{3}$

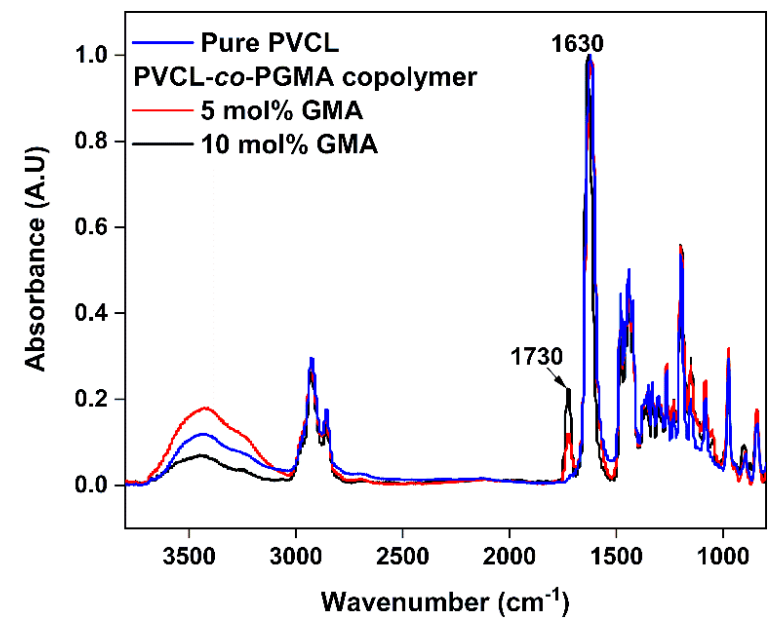

Figure S 4. FTIR spectra of pure PVCL and PVCL-co-PGMA copolymers (VG 5 : 5 mol\% GMA and $\mathrm{VG}_{10}: 10 \mathrm{~mol} \% \mathrm{GMA}$ ) 
As it was difficult to calculate the exact amount of GMA incorporated in PVCL-co-PGMA copolymers from ${ }^{1} \mathrm{H}$ NMR, a standard calibration line was drawn from FTIR by taking known amount of GMA content (see Figure S 5). The details are described below. With the help of this equation the real amount of GMA content as calculated and tabulated in Table $\mathbf{S} \mathbf{1 .}$
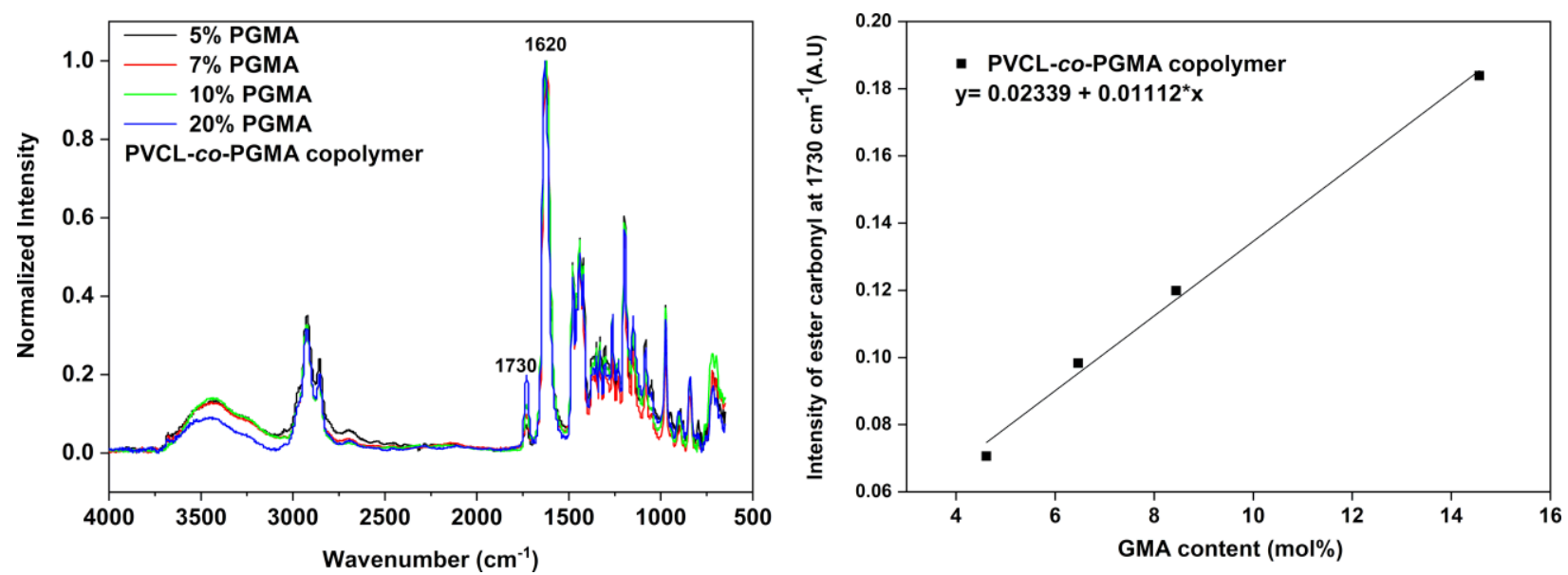

Figure S 5. (a) FTIR spectra of PVCL-co-PGMA copolymers with known GMA content and (b) calibration line drawn to calculate the exact amount of GMA in copolymer

Cloud point measurement of PVCL-co-PGMA copolymers. As PVCL is a thermoresponsive polymer that exhibits LCST (phase separation occurs at high temperature), above which polymer solution becomes turbid from a transparent solution, it was worth to observe how the addition of a new component (PGMA segment) effects the LCST point. It was interesting to notice that small amount of PGMA brought a significant change in LCST compared to Pure PVCL. As PGMA is more hydrophobic than PVCL, it helped PVCL to interact with water easily and as a result, LCST value was shifted towards lower temperatures (see Figure $\mathbf{S}$ 6), suggesting the successful incorporation of PGMA group on PVCL polymer backbone. 


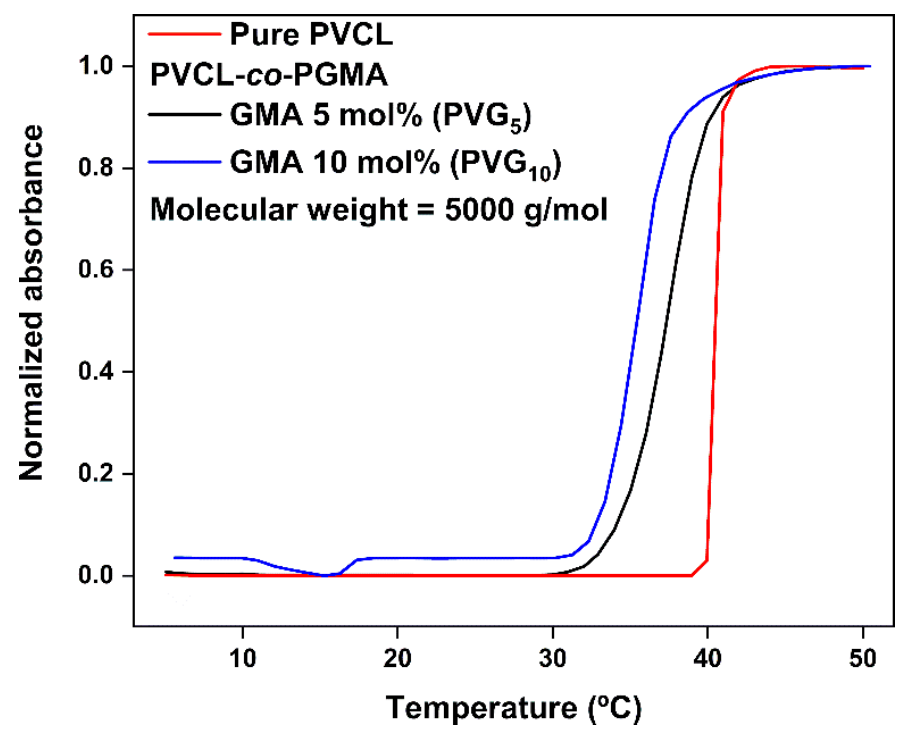

Figure S 6. Cloud point comparison between pure PVCL $\left(40^{\circ} \mathrm{C}\right)$ and PVCL-co-PGMA copolymers (molecular weight $5000 \mathrm{~g} / \mathrm{mol})$ : (VG5: 5 mol\% GMA; $\left(37^{\circ} \mathrm{C}\right)$ and $\mathrm{VG}_{10}: 10 \mathrm{~mol} \%$ GMA; $\left.\left(35^{\circ} \mathrm{C}\right)\right)$

\section{Synthesis of poly(sulfobetaine) homopolymer (PSB macro-RAFT). The RAFT-Agent} CPCPA with the initiator ABCVA and the monomer SB was dissolved in a water and acetone mixed solvent. The whole mixture was then purged under nitrogen atmosphere for $30 \mathrm{~min}$ and the reaction was put in a pre-heated oil bath at $70^{\circ} \mathrm{C}$ and stirred for $18 \mathrm{~h}$. The polymer was precipitated from cold methanol to obtain the reddish solid product, which was dried at $45^{\circ} \mathrm{C}$ in a vacuum oven under reduced pressure over night (see Scheme S 3). For the purification of the polymer, the product was re- dissolved in water and dialyzed in a regenerated cellulose membrane with a molecular weight cut off (MWCO) 3500 Da for $4 \mathrm{~d}$ followed by freeze drying to obtain a pinkish red powder yielding $80-85 \%$ of product. The details of the PSB macro-RAFT reaction are given in Table $\mathbf{S} 2$. 


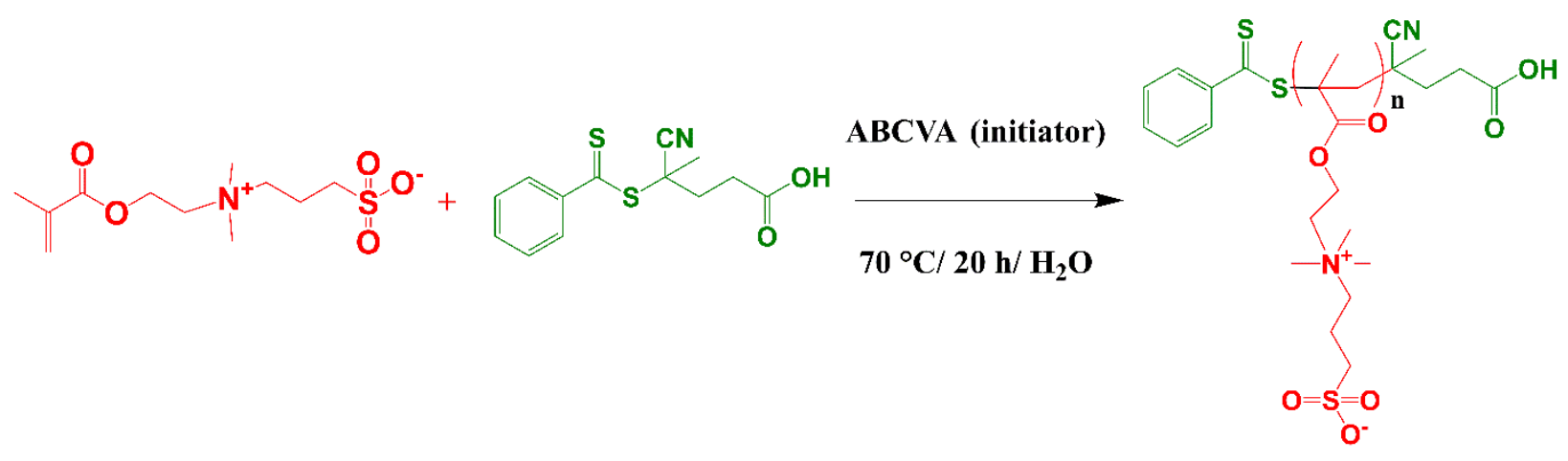

Scheme S 3. Synthesis outline of PSB macro-RAFT (homopolymer)

Table S 2. Molar composition of PSB macro-RAFT homopolymer synthesis

\begin{tabular}{|c|c|c|c|c|c|c|c|c|c|}
\hline Sample & $\begin{array}{c}\text { Target } \\
\text { molecular } \\
\text { weight (g/ } \\
\text { mol) }\end{array}$ & $\begin{array}{l}\text { SB } \\
\text { (g) }\end{array}$ & $\begin{array}{c}\text { CPCPA } \\
\text { RAFT } \\
\text { (g) }\end{array}$ & $\begin{array}{c}\text { ABCVA } \\
\text { (g) }\end{array}$ & $\begin{array}{c}\text { Water } \\
(\mathrm{mL})\end{array}$ & $\begin{array}{c}\text { Acetone } \\
(\mathrm{mL})\end{array}$ & $\begin{array}{c}\text { Molecular } \\
\text { weight } \\
\text { from } \\
\text { NMR } \\
\text { (g/mol) } \\
\text { Mn, NMR }\end{array}$ & $\begin{array}{c}\text { Molecular } \\
\text { weight } \\
\text { from } \\
\text { GPC } \\
\text { (g/mol) } \\
\text { Mn, GPC }^{\text {met }}\end{array}$ & $\begin{array}{l}\text { PDI } \\
\text { (Đ) }\end{array}$ \\
\hline $\begin{array}{l}\text { PSB } \\
5000\end{array}$ & 5000 & 1.000 & 0.056 & 0.014 & 1.7 & 0.5 & 5371 & 5230 & 1.11 \\
\hline $\begin{array}{c}\text { PSB } \\
10000\end{array}$ & 10000 & 1.000 & 0.029 & 0.007 & 2.2 & 0.3 & 11219 & 8978 & 1.16 \\
\hline
\end{tabular}
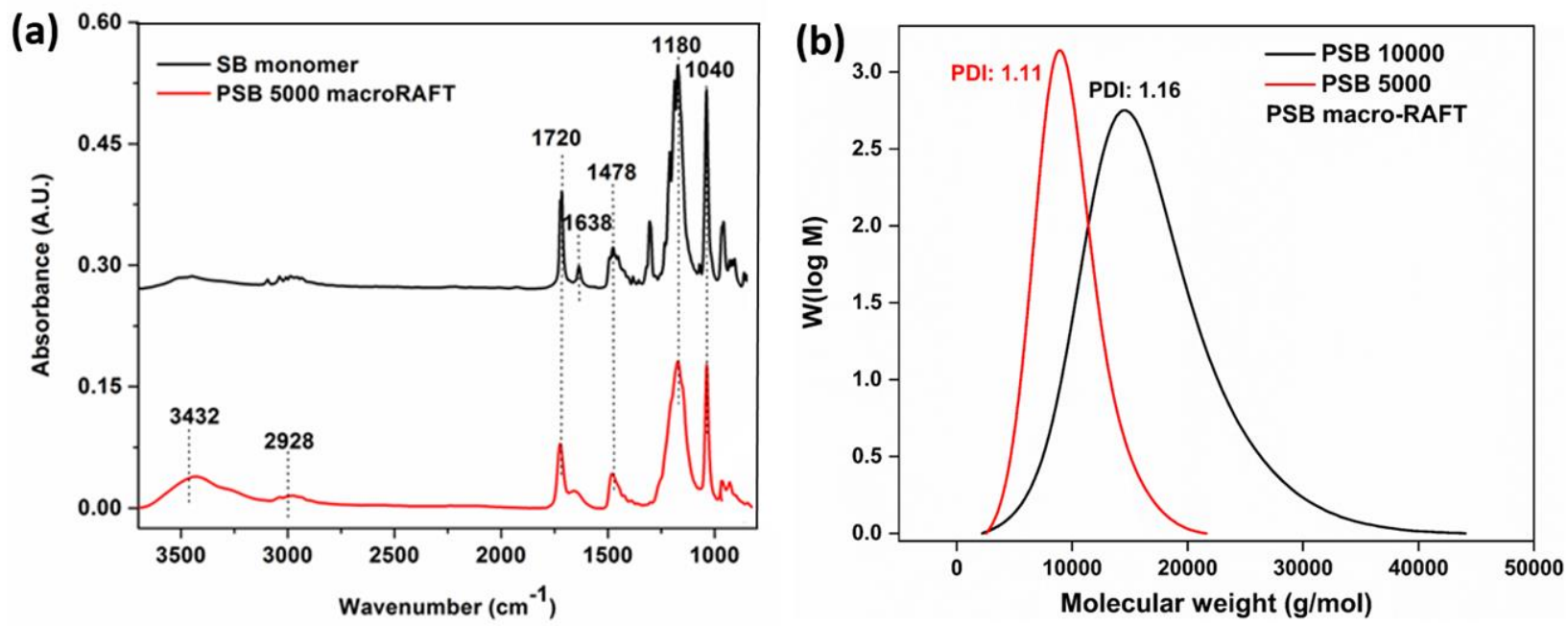

Figure S 7. (a) FTIR spectra of SB monomer and PSB 5000 macro-RAFT (b) GPC diagram of different PSB macro-RAFTs 
Figure S 7a shows the FTIR spectral comparison between SB monomer and PSB macro-RAFT where presence of at 1720,1180 and $1040 \mathrm{~cm}^{-1}$ due to ester carbonyl, sulfonate asymmetric st. and symmetric st. respectively confirm that during the RAFT polymerization of sulfobetaine the Zwitterionic group remained intact. Disappearance of the peak at $1638 \mathrm{~cm}^{-1}(>\mathrm{C}=\mathrm{C}<$ unsaturation) in the PSB macro-RAFT FTIR spectrum suggests the appreciable conversion of SB monomer to PSB homopolymer.

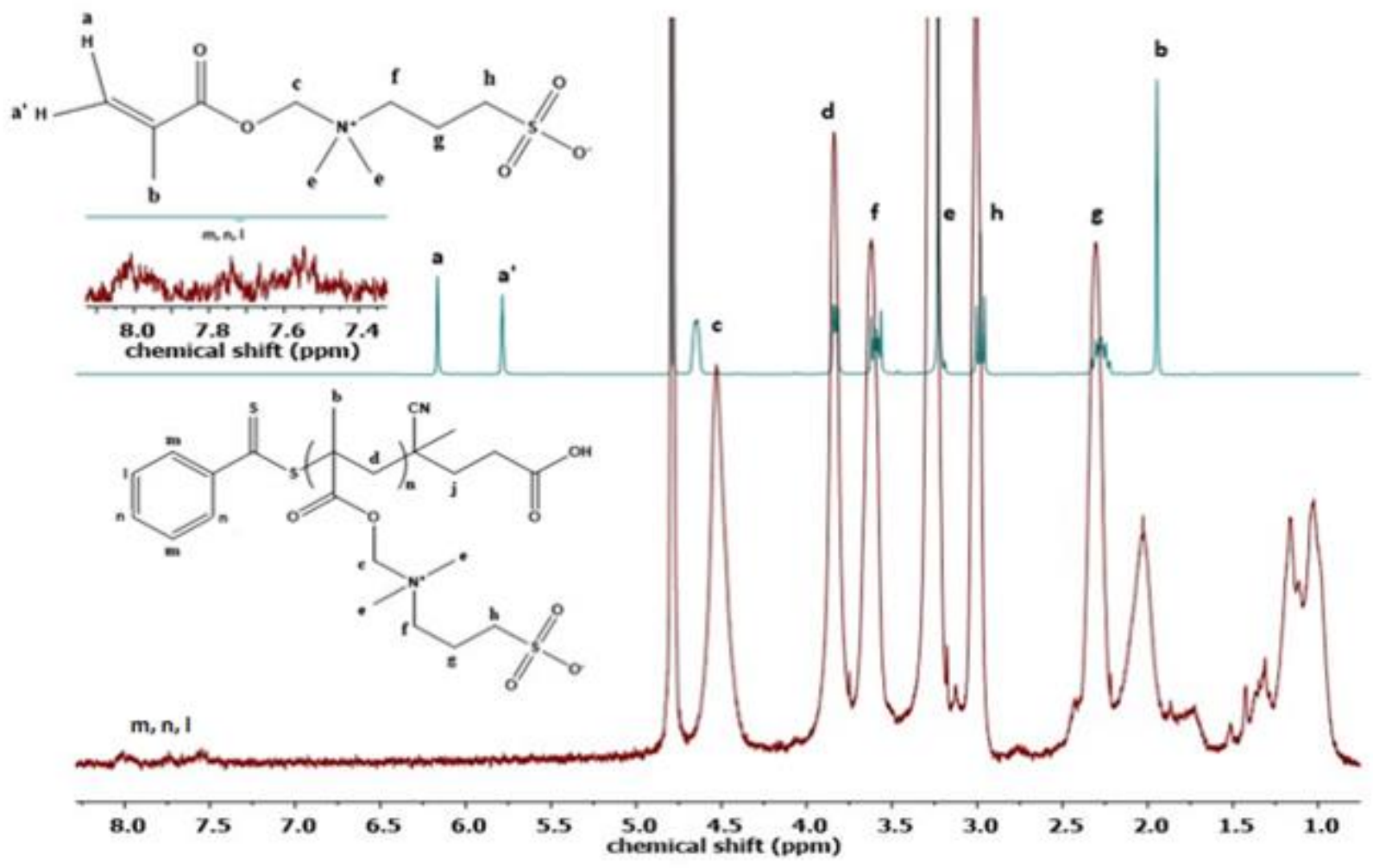

Figure S 8. ${ }^{1} \mathrm{H}$ NMR spectral comparison between SB monomer and PSB 5000 macro-RAFT

Further ${ }^{1} \mathrm{H}$ NMR analysis was carried out to observe the presence of the RAFT moiety (with phenyl end group) and Figure $\mathbf{S} \mathbf{8}$ shows that no vinylic proton is present in the polymer spectrum and additionally appearance of phenyl group at 7.5-8.0 ppm region suggests the successful incorporation of RAFT moiety at the tail end of PSB homopolymer. With the help of that peak integral area, molecular weight $\left(\mathrm{M}_{\mathrm{n}}\right)$ was calculated, which was quite similar to the molecular 
weight obtained from water GPC result $\left(\mathrm{M}_{\mathrm{GPC}}\right)$ of PSB homopolymers (see Table $\mathbf{S} 2$ ) with low PDI and unimodal distribution.

\section{Synthesis of thiol ended poly(sulfobetaine) (PSB -SH) by end group removal of PSB macro-}

RAFT. The end group modification of a RAFT polymer was performed according to Lowe et al. Under nitrogen atmosphere, an aqueous solution of sodium borohydride $\left(\mathrm{NaBH}_{4}\right)(25$ eq.) was added to an aqueous solution of PSB macro-RAFT and stirred for $48 \mathrm{~h}$ to ensure the complete removal of RAFT moiety from the tail-end of PSB macro-RAFT. The solution was dialyzed in a regenerated cellulose membrane with MWCO 3500 Da for $4 \mathrm{~d}$ (see Scheme S 4). Thereafter, the solution was freeze dried to obtain off-white powder, PSB-SH. The reaction details are described in the following Table $\mathbf{S} 3$.
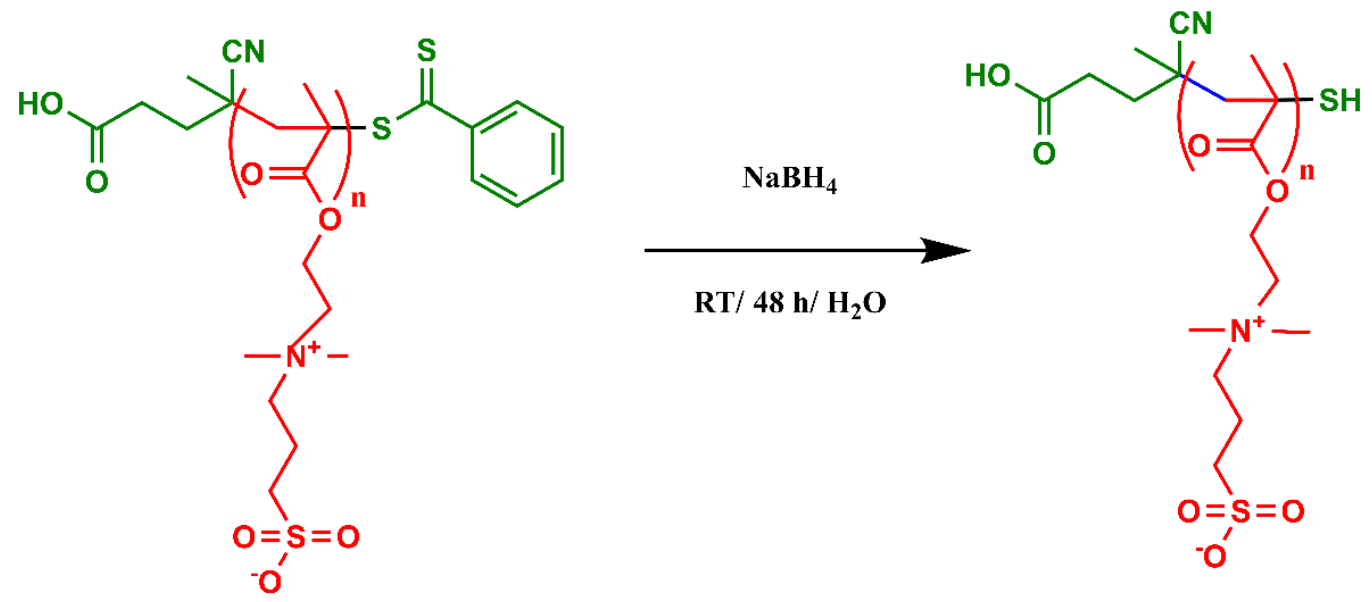

Scheme S 4. Synthesis outline of end-group removal of PSB macro-RAFT

Table S 3. Molar composition of PSB macro-RAFT end group removal

\begin{tabular}{ccccc}
\hline Sample & $\begin{array}{c}\text { PSB molecular } \\
\text { weight }(\mathbf{g} / \mathbf{m o l})\end{array}$ & $\begin{array}{c}\text { PSB macro- } \\
\text { RAFT }(\mathbf{g})\end{array}$ & NaBH4 $_{\mathbf{4}}(\mathbf{g})$ & Water (mL) \\
\hline PSB-SH 5000 & 5000 & 1.000 & 0.227 & 7.5 \\
\hline PSB-SH 10000 & 10000 & 1.000 & 0.115 & 7.5 \\
\hline
\end{tabular}


${ }^{1}$ H NMR spectra analysis of thiol ended poly(sulfobetaine) (PSB-SH). As the PSB homopolymers contained phenyl group at the tail-end of RAFT and its presence was confirmed by ${ }^{1} \mathrm{H}$ NMR spectrum, so after the cleavage of that end group, no such peak was observed at 7.5- 8.0 ppm in the PSB-SH ${ }^{1} \mathrm{H}$ NMR spectrum (see Figure S 9).

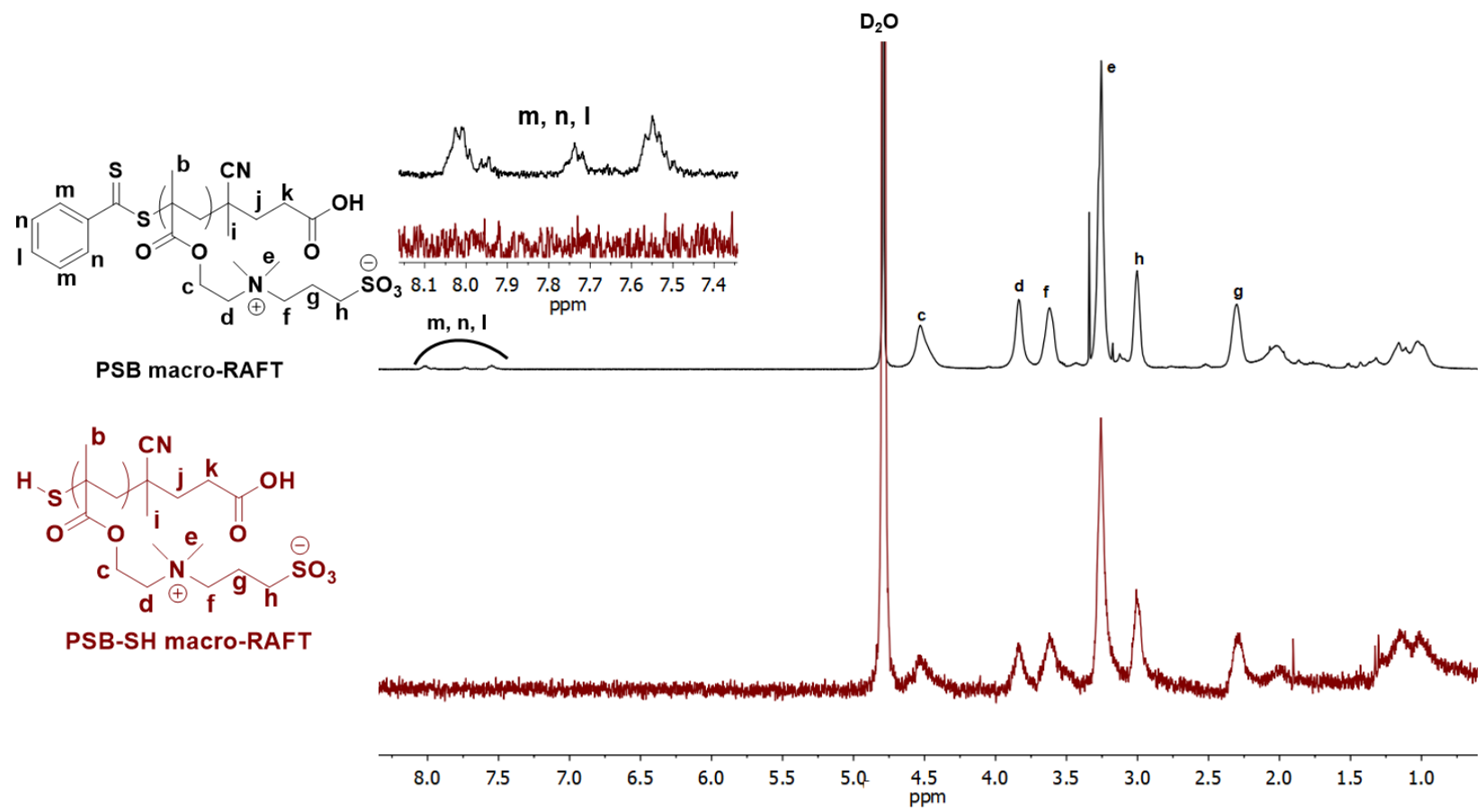

Figure S 9. ${ }^{1} \mathrm{H}$ NMR spectra of PSB macro-RAFT and PSB-SH (after end group removal)
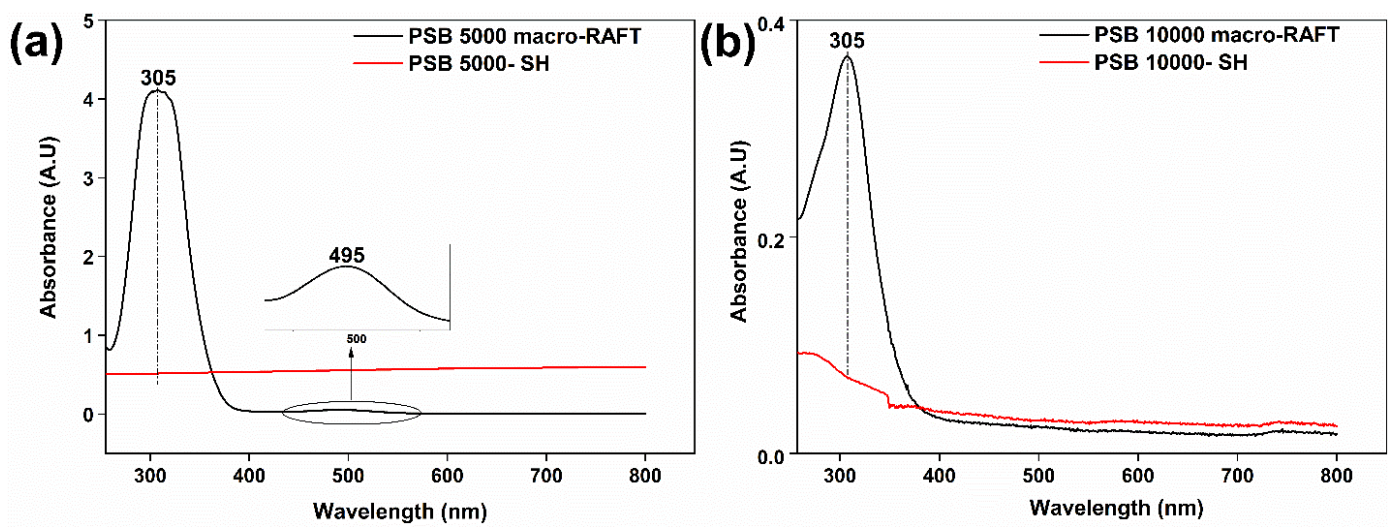

Figure S 10. UV-vis analyses of end group removal of different molecular weighed PSB macro- RAFTs (a) 5000 and (b) $10000 \mathrm{~g} / \mathrm{mol}$ 
Removal of end group of PSB macro-RAFT was also confirmed by UV-vis analysis. Due to presence of phenyl moiety at the chain end, it shows peak at around $305 \mathrm{~nm}\left(\pi-\pi^{*}\right.$ transition) and $495 \mathrm{~nm}\left(\mathrm{n}-\pi^{*}\right.$ transition) wavelengths. However, once the end group was cleaved by $\mathrm{NaBH}_{4}$ reduction, those characteristic signals were disappeared, which suggests the successful formation of PSB-SHs upon removal of RAFT end group from their corresponding PSB macro-RAFTs (see Figure S 10).

Synthesis of PVCL-co-PGMA-g-PSB graft copolymer by thiol-epoxy click reaction. The PVCL-co-PGMA polymer dissolved in a mixture of water and acetone was added to a $\mathrm{NaOH}$ solution (0.02 wt. \%) of PSB-SH and stirred at RT for $24 \mathrm{~h}$ (see Scheme S 5). The solution is dialyzed in a membrane with a MWCO of 12000-14000 Da for $4 \mathrm{~d}$ to obtain the grafted PSB on the backbone of PVCL- co- PGMA copolymer. It was then freeze-dried to obtain white powder, PVCL- co- PGMA- $g$-PSB. A detailed reaction composition is given in the following Table S 4.
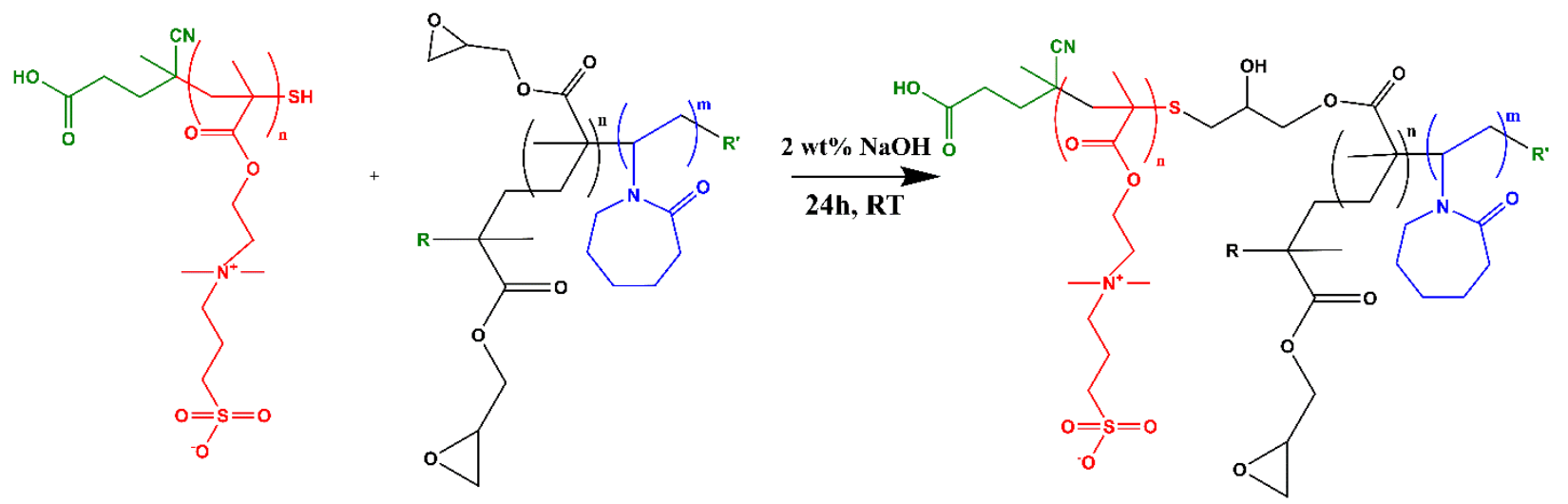

Scheme S 5. Reaction scheme of the synthesis of PVCL-co-PGMA-g-PSB by partial substitution of GMA by thiol-epoxy click reaction 
Table S 4. Molar composition of PVCL-co-PGMA-g-PSB graft copolymer synthesis

\begin{tabular}{|c|c|c|c|c|c|c|c|c|}
\hline Sample & $\begin{array}{l}\text { PVG }^{*} \\
\text { copolymer } \\
(\mathrm{mg})\end{array}$ & $\begin{array}{c}\mathrm{H}_{2} \mathrm{O} \\
(\mathrm{mL})\end{array}$ & $\begin{array}{c}\text { Acetone } \\
(\mathbf{m L})\end{array}$ & $\begin{array}{c}\text { Amount } \\
\text { of GMA } \\
\text { present } \\
\text { in PVGm }{ }^{\#} \\
(\mathbf{m o l} \%)\end{array}$ & $\begin{array}{c}\text { Partial } \\
\text { grafting of } \\
\text { GMA by } \\
\text { PSB-SH } \\
(\mathrm{mol} \%) \\
\end{array}$ & $\begin{array}{l}\text { PSB- } \\
\text { SH } \\
\text { (mg) }\end{array}$ & $\begin{array}{c}\text { PSB-SH } \\
\text { molecular } \\
\text { weight } \\
(\mathrm{g} / \mathrm{mol})\end{array}$ & $\begin{array}{c}\text { NaOH } \\
\text { solution } \\
\text { (mL) }\end{array}$ \\
\hline$(\mathrm{PVGS3})_{5000}$ & 100 & 4 & 0.2 & 6 & 3 & 110 & 5000 & 4.2 \\
\hline$(\mathrm{PVGS5})_{5000}$ & 100 & 4 & 0.2 & 8 & 5 & 180 & 5000 & 6.8 \\
\hline$(\mathrm{PVGS} 3)_{10000}$ & 100 & 4 & 0.2 & 6 & 3 & 210 & 10000 & 3.5 \\
\hline$($ PVGS5) 10000 & 100 & 4 & 0.2 & 8 & 5 & 350 & 10000 & 5.0 \\
\hline
\end{tabular}

$\mathrm{PVG}^{*}{ }_{\mathrm{n}}$ represents PVCL-co-PGMA random copolymer where ' $\mathrm{n}$ ' stands for GMA present theoretically in the copolymer composition and $\mathrm{PVG}^{\#}$ represents PVCL-co-PGMA random copolymer where ' $\mathrm{m}$ ' stands for exact GMA present in the copolymer composition, calculated from the FTIR calibration line (see Figure S 5)

The synthesized graft copolymers, PVCL-co-PGMA-g-PSB with varying amount and molecular weight of partially grafted PSB-SH were systematically investigated by ${ }^{1} \mathrm{H}$ NMR and FTIR studies to find the successful incorporation of PSB inside the PVCL-co-PGMA random copolymer backbone and the exact incorporation of PSB-SH was also quantified with ${ }^{1} \mathrm{H}$ NMR study (see Table S 5). 

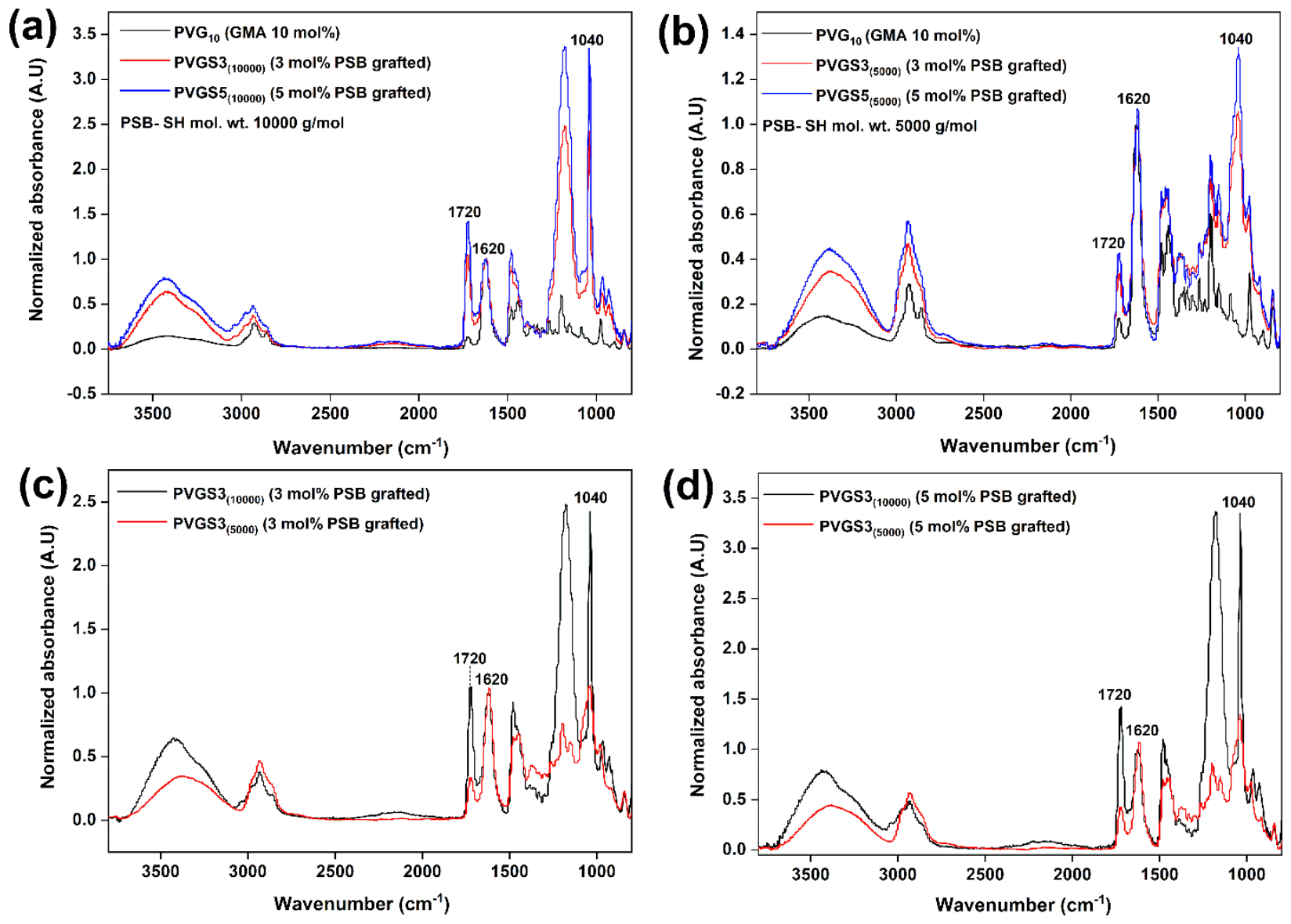

Figure S 11. FTIR spectral comparison of PVCL-co-PGMA-g-PSB graft copolymers:

synthesized with 3 and $5 \mathrm{~mol} \%$ of PSB-SH (a) molecular weight 10000 (b) $5000 \mathrm{~g} / \mathrm{mol}$;

synthesized with different PSB-SH molecular weight (5000 and $10000 \mathrm{~g} / \mathrm{mol}$ ): (c) $3 \mathrm{~mol} \% \mathrm{PSB}-$

SH and (d) 5 mol\% PSB-SH

FTIR study with the PVCL-co-PGMA-g-PSB copolymers showed the successful PSB loading on the PVCL-co-PGMA copolymer when both the molecular weight and amount of PSB-SH were varied during the thiol-epoxy grafting process as the intensities of the characteristic peak of PSB (1720 and $1040 \mathrm{~cm}^{-1}$ ester carbonyl and sulfonate symmetric stretching) were increased. Interestingly, an increase in concentration and molecular weight of PSB-SH resulted in a more efficient incorporation of zwitterionic group on the copolymer backbone. Irrespective of molecular weight the $5 \mathrm{~mol} \%$ PSB-SH sample showed stronger FTIR signal intensity than $3 \mathrm{~mol} \%$ one (see 
Figure S 11a and b) and on the other hand, irrespective of mol\% of PSB-SH used $10000 \mathrm{~g} / \mathrm{mol}$ sample showed stronger FTIR signal intensity than $5000 \mathrm{~g} / \mathrm{mol}$ one (see Figure S 11c and d).

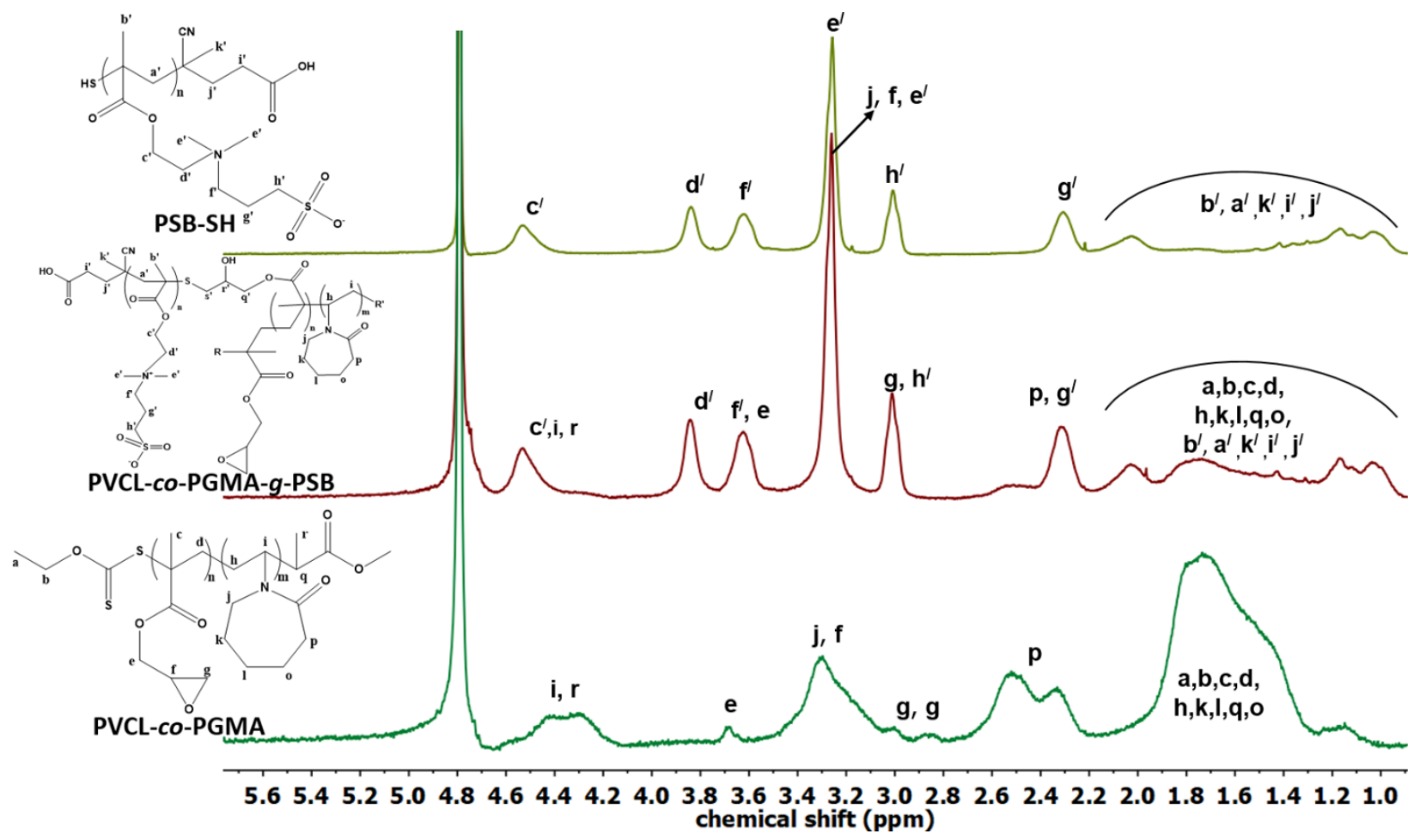

Figure S 12: ${ }^{1} \mathrm{H}$ NMR spectra of PSB-SH 10000, PVCL-co-PGMA (10 mol\% GMA) and PVCL-co-PGMA-g-PSB (5 mol\% PSB-SH 10000)

The proton NMR spectra was also done to see the partial grafting of PSB-SH on PVG copolymer backbone (see Figure S 12). The study shows that all the characteristic peak signals of PSB were integrated in the PVCL-co-PGMA-g-PSB proton NMR, where signal of proton $\mathbf{d}^{\prime}$, exclusively coming from PSB was taken into account along with the proton signals $\mathbf{p}$ and $\mathbf{g}^{\prime}$, coming from both PVCL and PSB to calculate the real amount of grafted PSB on the PVG copolymer backbone. Although it was difficult to find the left over PGMA peak signals in the graft copolymer by proton NMR spectral study, so attention has been paid to the FTIR study before going to the microgel 
formation reaction where the rest of the GMA amount would be used for crosslinking with 1,6hexamethylene diamine.

Table S 5. Molar composition of PSB-SH grafted on PVG copolymer backbone, calculated by

${ }^{1} \mathrm{H}$ NMR of PVCL-co-PGMA-g-PSB graft copolymer

\begin{tabular}{cccc}
\hline Sample & $\begin{array}{c}\text { Amount of } \\
\text { GMA } \\
\text { present in } \\
\text { PVG } \\
\text { copolymer } \\
(\mathbf{m o l} \%)\end{array}$ & $\begin{array}{c}\text { Theoretical } \\
\text { amount of } \\
\text { PSB-SH } \\
\text { grafted } \\
\text { (mol\%) }\end{array}$ & $\begin{array}{c}\text { Exact } \\
\text { amount of } \\
\text { PSB-SH } \\
\text { grafted } \\
\text { (mol\%) }\end{array}$ \\
\hline$($ PVGS3) 5000 & 10 & 3 & 2.8 \\
\hline$($ PVGS5) 5000 & 10 & 5 & 4.5 \\
\hline$($ PVGS3) 10000 & 10 & 3 & 3.3 \\
\hline (PVGS5) 10000 & 10 & 5 & 5.7 \\
\hline
\end{tabular}

A close look at the Figure $\mathbf{S} \mathbf{1 3}$ reveals that the partial substitution of GMA by PSB-SH was successful because the trace amount of GMA is still left as the characteristic signal of PGMA at $845 \mathrm{~cm}^{-1}$ due to asymmetric contraction of oxirane ring is observable (see inset Figure S 13). It was also worthwhile to notice that higher amount of PSB grafted PVCL- co-PGMA- $g$-PSB graft copolymer shows a weaker left over GMA signal (at $845 \mathrm{~cm}^{-1}$ ) than the lower amount of PSB grafted sample. This finding clearly suggests the presence of free GMA group in the graft copolymers in a proportional ratio that can be used for next phase of crosslinking reaction. 


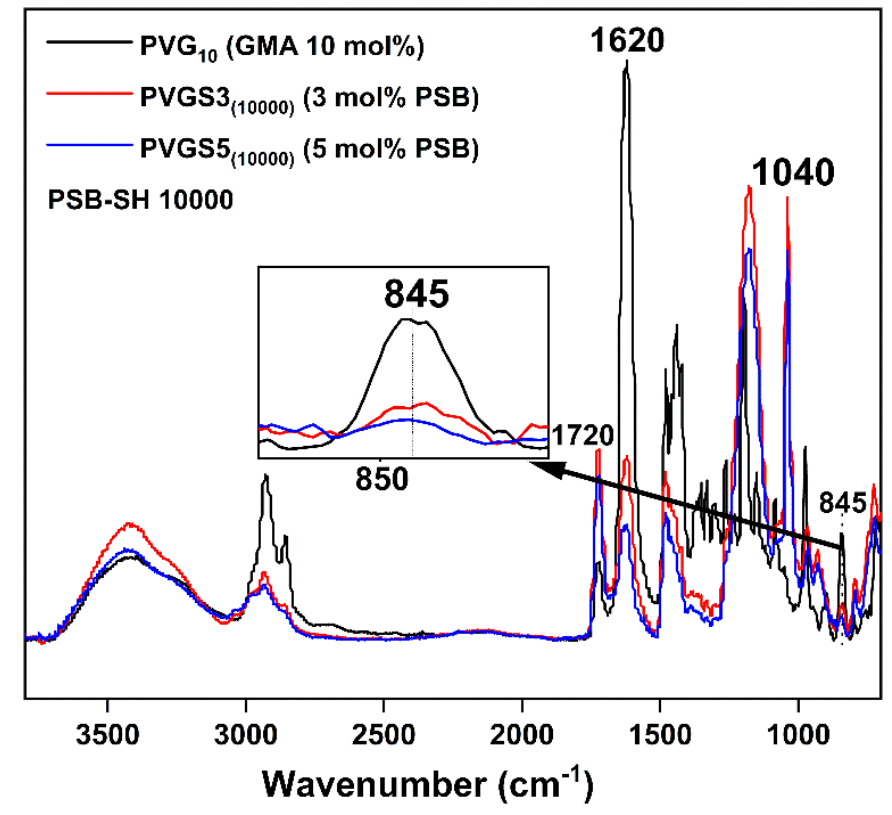

Figure S 13. FTIR spectral comparison between PVG copolymer and PVGS graft copolymer showing the consumption of GMA group

Synthesis of microgel by amine-epoxy crosslinking with residual GMA group. The grafted Product, PVCL-co-PGMA-g-PSB graft copolymer was dissolved in water along with the crosslinker 1,6- hexadiamine (6 wt\%). The aqueous solution mixture was added to toluene (oil phase) containing Span 80 as surfactant and a mini-emulsion was obtained by a 10 min ultrasound sonication at an energy level of 40\% using a W-250 D Branson Digital Sonifier. To keep the solution cool the flask was placed under ice bath. After that, the emulsion was transferred to a stirring plate to react for 24 hours at room temperature. The emulsion was broken by centrifugation at $11000 \mathrm{rpm}$ by adding $5 \mathrm{~mL}$ of ethanol for first 15 minutes using a Heraeus Multifuge X3R centrifuge (Thermo Scientific). The settled mass was washed twice with $10 \mathrm{~mL}$ toluene and each time followed by a centrifugation to get rid of the surfactant and unreacted materials as much as possible. The solid residue was kept under fume hood overnight to evaporate the rest of the toluene and re-dissolved in water followed by dialysis in a MWCO 120000- 14000 Da membrane for $7 \mathrm{~d}$ 
against water. Finally, the solution was freeze dried to obtain the dry microgel powder. The detail reaction composition is given in the Table $\mathbf{S} \mathbf{6}$.
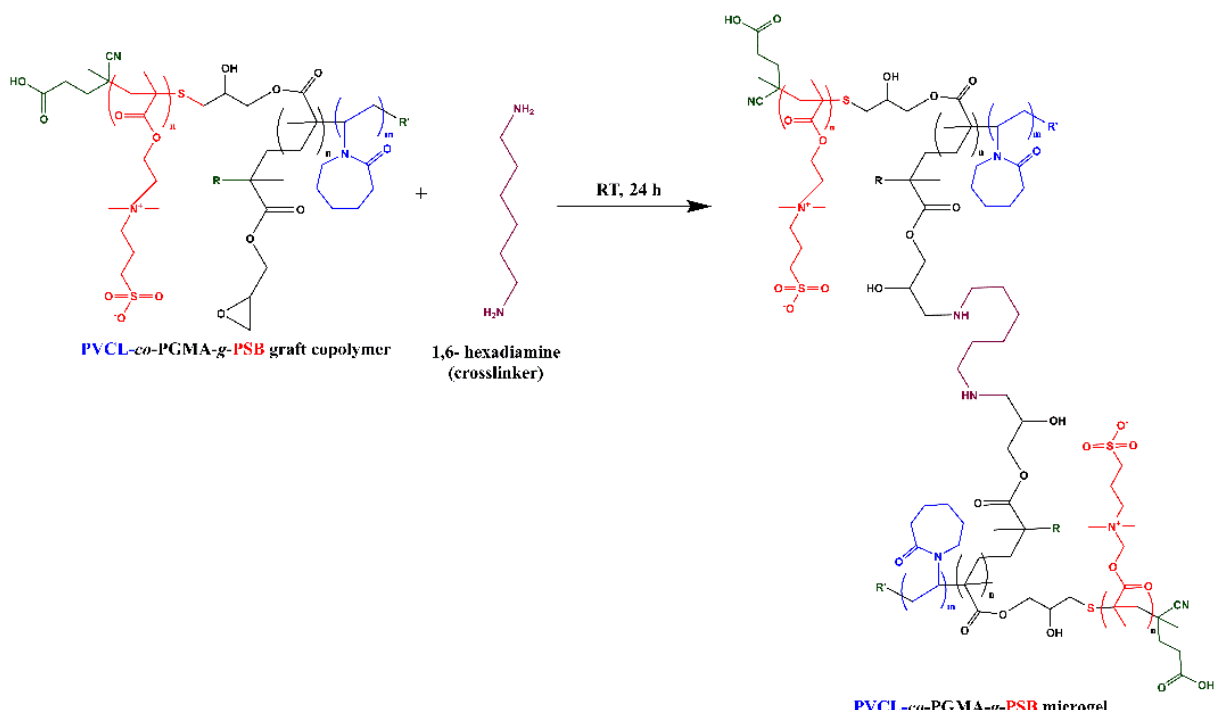

Scheme S 6. Synthesis outline for PVCL-co-PGMA-g-PSB microgel from zwitterionic graft copolymer

Table S 6. Molar composition of PVCL-co-PGMA-g-PSB microgel synthesis

\begin{tabular}{|l|c|c|c|c|c|c|}
\hline Sample & $\begin{array}{c}\text { Graft } \\
\text { copolymer }\end{array}$ & $\begin{array}{c}\text { Amount } \\
\text { of graft } \\
\text { copolymer } \\
\text { (mg) }\end{array}$ & $\begin{array}{c}\text { Amount of } \\
\text { crosslinker } \\
\text { (mg) }\end{array}$ & $\begin{array}{c}\text { Amount } \\
\text { of } \\
\text { water } \\
\text { (mL) }\end{array}$ & $\begin{array}{c}\text { Amount } \\
\text { of } \\
\text { toluene } \\
\text { (mL) }\end{array}$ & $\begin{array}{c}\text { Amount } \\
\text { of Span } \\
\mathbf{8 0} \text { (mg) }\end{array}$ \\
\hline MG-1 & (PVGS3) $5000_{50}$ & 50 & 3 & 1.5 & 15 & 65 \\
\hline MG-2 & $($ PVGS5) 5000 & 50 & 3 & 1.8 & 18 & 78 \\
\hline MG-3 & (PVGS3) $)_{10000}$ & 100 & 6 & 2 & 20 & 87 \\
\hline MG-4 & (PVGS5) 10000 & 100 & 6 & 2 & 20 & 87 \\
\hline
\end{tabular}

The zwitterionic microgels were also characterized by NMR to ensure that during crosslinking reaction, the zwitterionic group remained unchanged and the characteristic peak signals of crosslinker are integrated to the microgel spectra as the left over free GMA groups were reacted with the 1, 6-hexamethylene diamine crosslinker. 


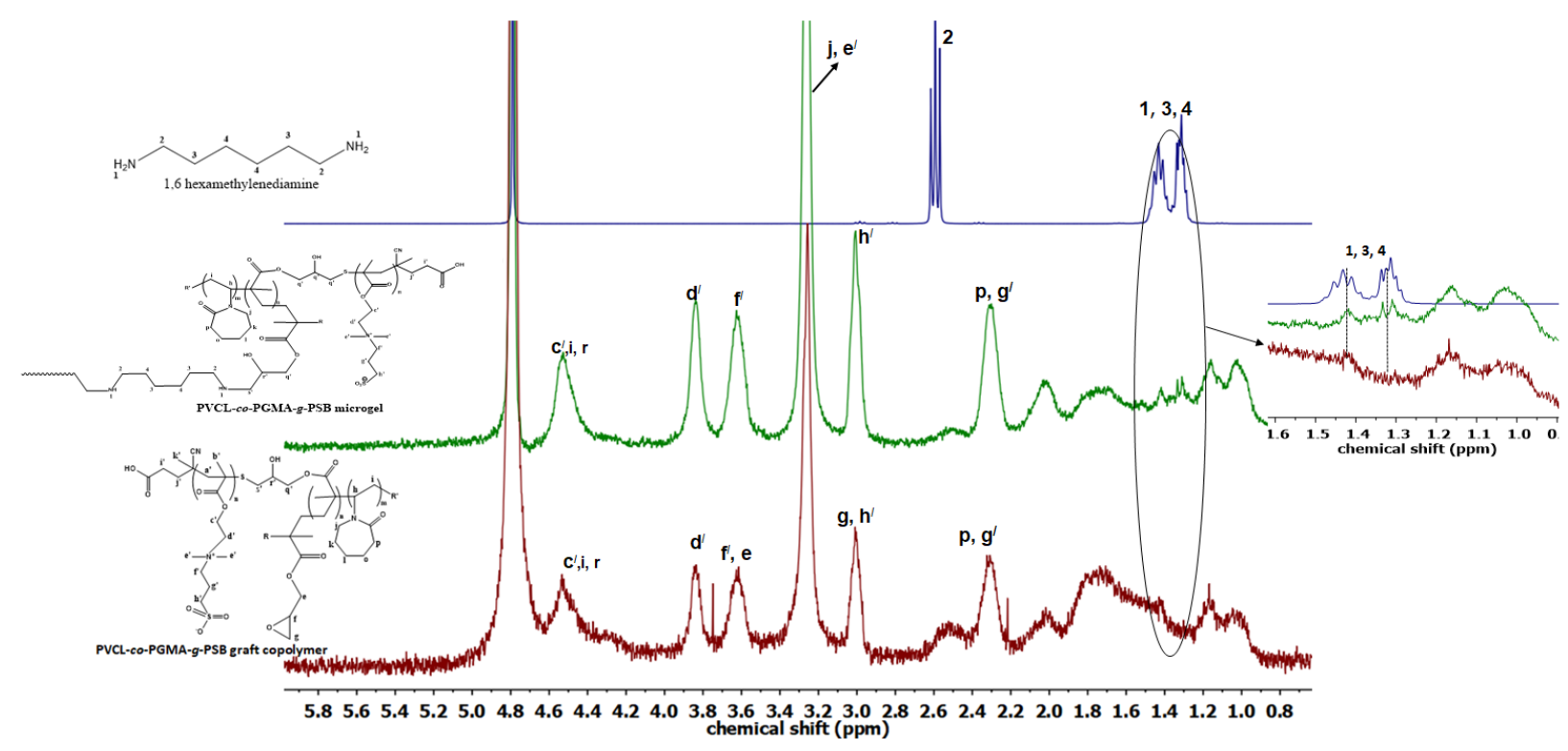

Figure S 14. ${ }^{1} \mathrm{H}$ NMR spectral comparison between 1,6-hexadiamine crosslinker, PVCL- co-

PGMA-g-PSB graft copolymer and corresponding microgel

From (Figure S 14) it can be seen that all of the characteristic proton peaks from graft copolymer are integrated to the microgel spectrum and additionally presence of crosslinker proton signal (1.30- $1.5 \mathrm{ppm}$ ) (see inset Figure $\mathbf{S}$ 14) proves the fact that PVCL-co-PGMA-g-PSB graft copolymer was converted to corresponding microgel by amine-epoxy crosslinking reaction.
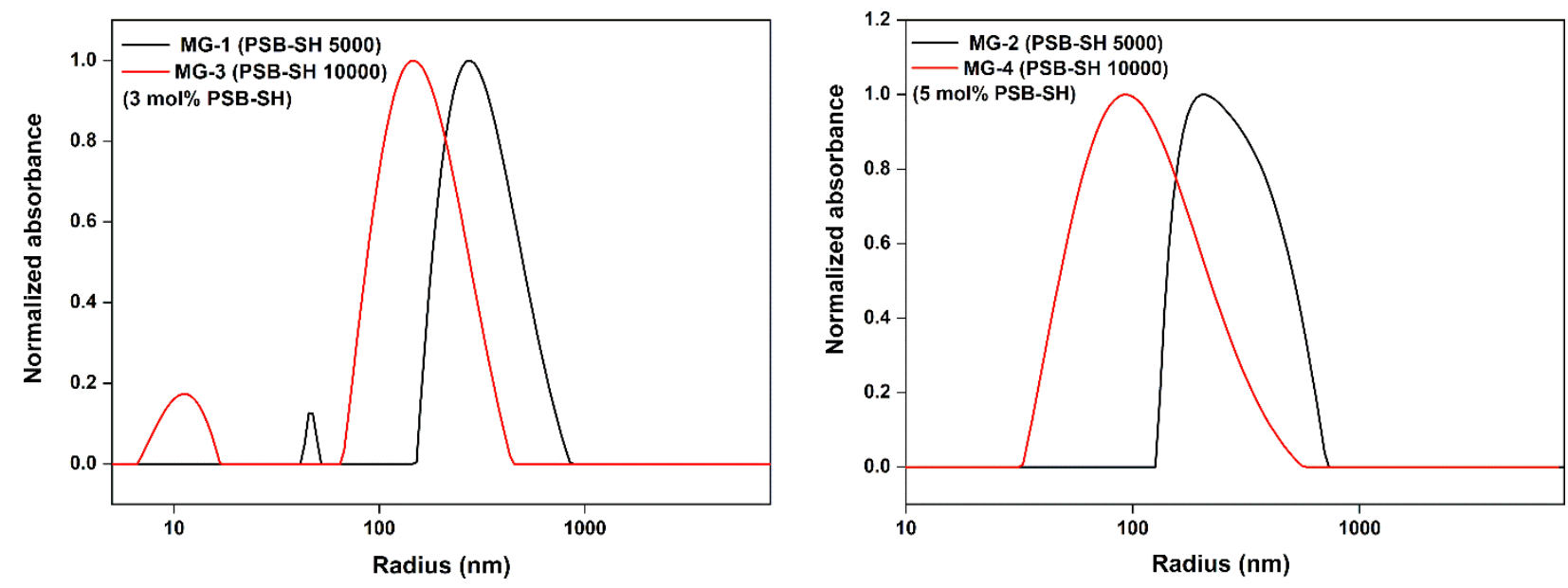

Figure S 15. Particle distribution index of different microgels 


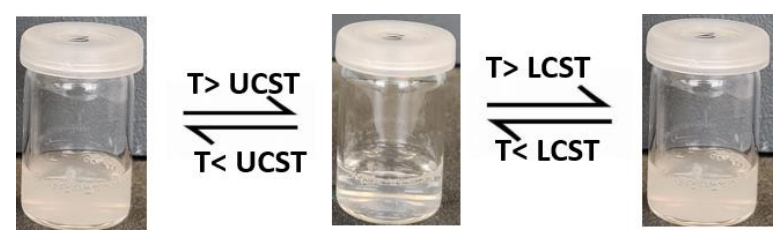

Figure S 16. Photograph of zwitterionic microgel (MG-4) below and above UCST and LCST

\section{AFM sample preparation.}

Surface Preparation: a square of $\mathrm{SiO}_{2}$ wafer $\left(1 \mathrm{~cm}^{2}\right.$ area) was cut, sonicated 15 minutes in pure acetone, dried with nitrogen flow and sonicated for another 15 minutes in pure Ethanol (then dried again under nitrogen flow).

Surface Silanization: $\mathrm{SiO}_{2}$ wafers were treated for activation with $300 \mathrm{sec}$ of air plasma (0.2 mbar) then put in $5 \mathrm{~mL}$ of a 2 vol\% TPTMS (3-mercaptopropyltrimethoxysilane) solution (in Ethanol) for 2 hours, rinsed with $9 \mathrm{~mL}$ of pure Ethanol and dried under nitrogen flow.

\section{Coating of microgels:}

MG4 single Particles: $50 \mu \mathrm{L}$ of a $0.1 \mathrm{mg} / \mathrm{mL}$ water dilution were spin coated on the silanized wafer at $2000 \mathrm{rpm}$ (800 rpms) for 1 minute.

MG-2 single Particles: $50 \mu \mathrm{L}$ of a $0.6 \mathrm{mg} / \mathrm{mL}$ water dilution were spin coated on the silanized wafer at $2000 \mathrm{rpm}(800 \mathrm{rpms})$ for 1 minute.

Pure PVCL: $50 \mu \mathrm{L}$ of a $1.5 \mathrm{mg} / \mathrm{mL}$ water dilution were spin coated on the non-silanized wafer at $2000 \mathrm{rpm}(800 \mathrm{rpms})$ for 1 minute.

PBS Treatment: To test the possibility of coating detachment, the wafers were immersed in 5 mL PBS Buffer ( $\mathrm{pH} 7.4$ ) for 36 hours then taken out let drying under the chemical hood covered in a box covered with filter paper. 


\section{QCM-D experiment.}

Sensor Cleaning: $\mathrm{SiO}_{2}$ sensors were irradiated 15 minutes with UV light and then immersed in $15 \mathrm{~mL}$ of a $2 \%$ sodium dodecyl sulfonate (SDS) solution for $45 \mathrm{~min}$, rinsed with pure water, and dried under nitrogen flow before being irradiated with UV light for another 15 minutes.

Surface Silanization: $\mathrm{SiO}_{2}$ sensors were treated for activation with $300 \mathrm{sec}$ of air plasma $(0.2$ mbar) then put in $5 \mathrm{~mL}$ of a 2 vol\% TPTMS (3-mercaptopropyltrimethoxysilane) solution (in Ethanol) for 2 hours, rinsed with $9 \mathrm{~mL}$ of pure Ethanol, and dried under nitrogen flow.

\section{Coating:}

- MG-4 single Particles: $50 \mu \mathrm{L}$ of a SDS water dilution were spin coated on the silanized wafer at $2000 \mathrm{rpm}(800 \mathrm{rpms})$ for 1 minute $(20 \mu \mathrm{L}$ SDS $0.42 \mathrm{mM}$ for every $110 \mu \mathrm{L}$ of MG-4 $4 \mathrm{mg} / \mathrm{mL}$ solution);

- $\quad$ Pure PVCL: $50 \mu \mathrm{L}$ of a $1.5 \mathrm{mg} / \mathrm{mL}$ water dilution were spin coated on the non-silanized sensor at $2000 \mathrm{rpm}(800 \mathrm{rpms})$ for 1 minute.
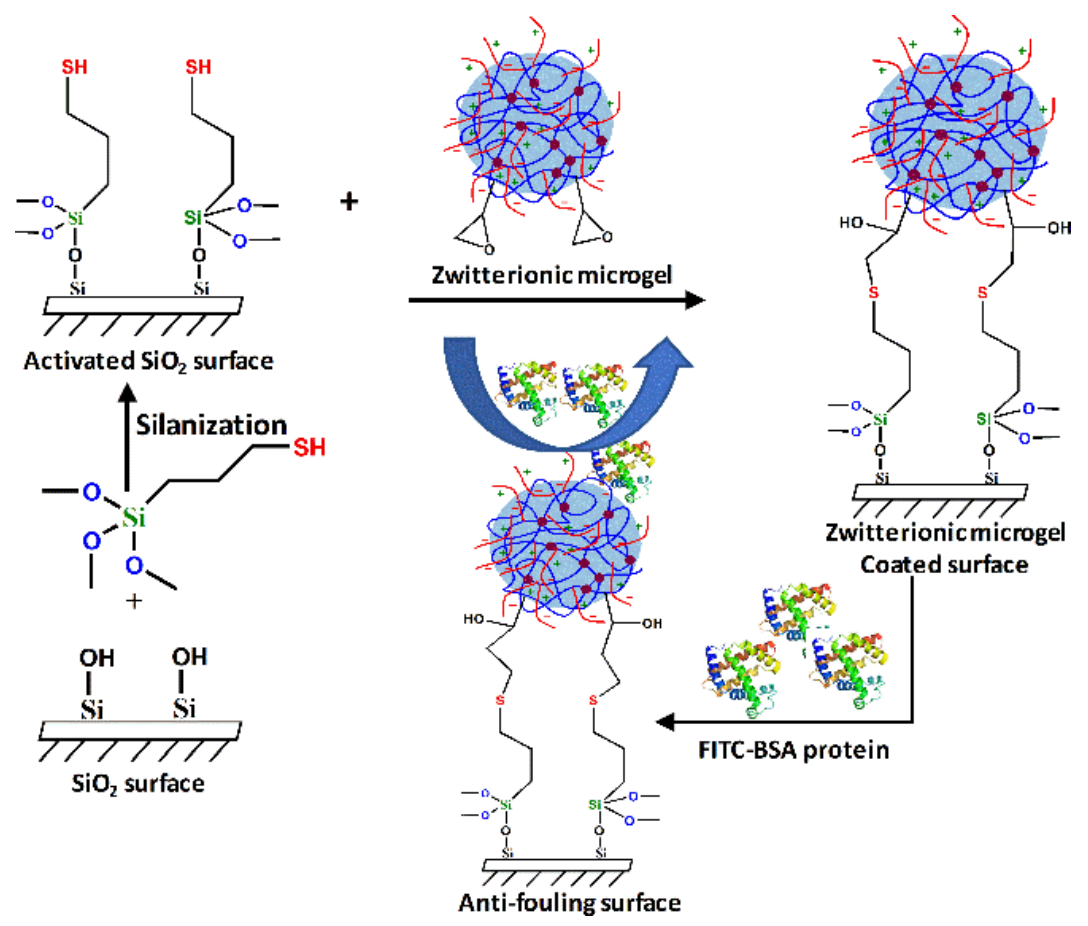

Scheme S 7. Schematic representation of microgel coating on surface for anti-fouling test 

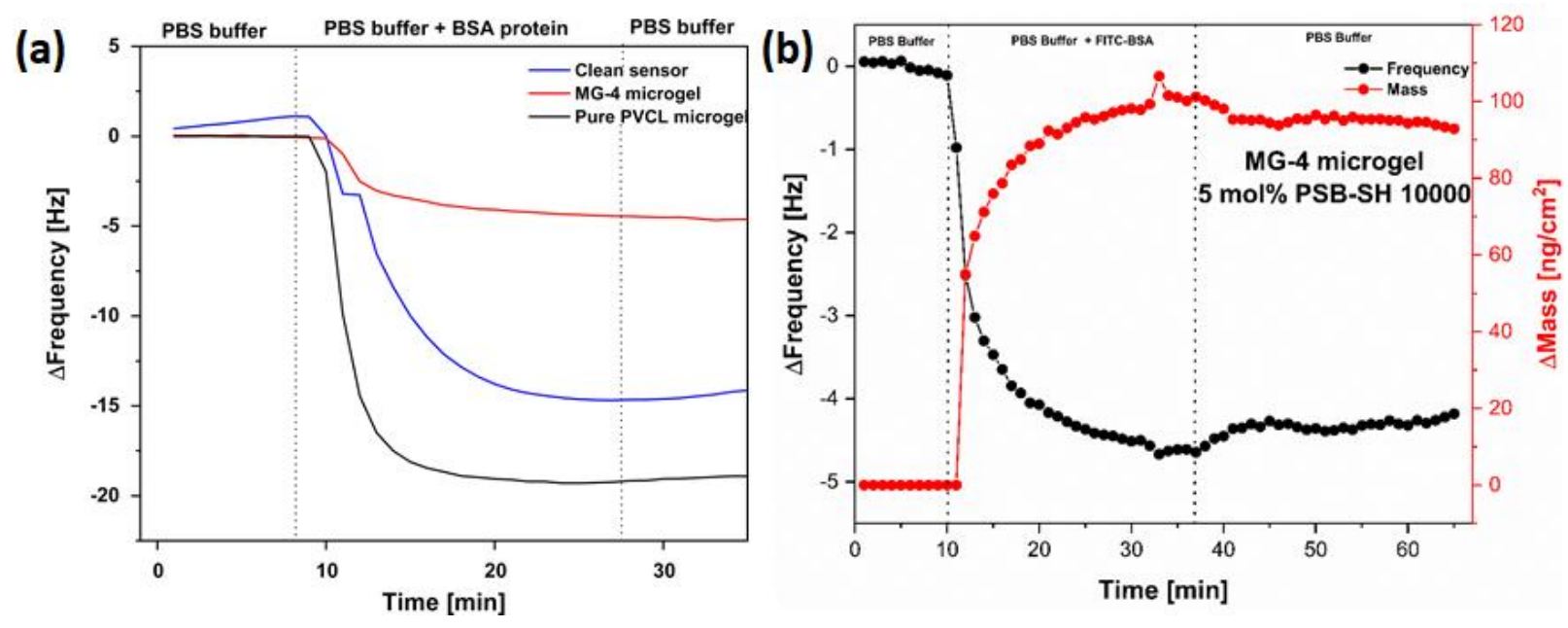

Figure S 17. (a) Plot of change in frequency after QCMD test on a clean sensor, pure PVCL microgel and MG-4 zwitterionic microgel coated sensors (b) plot of both frequency and mass of MG-4 microgel coated sensor
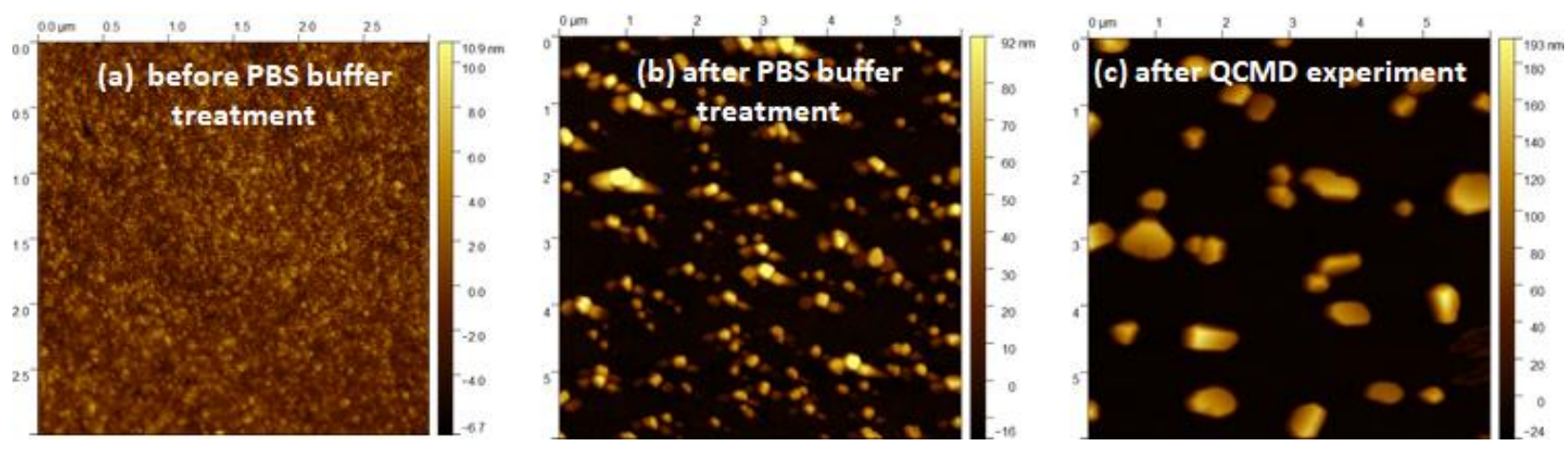

Figure S 18. AFM images of MG-4 microgel (5 mol\% PSB-SH 10000) coated on $\mathrm{SiO}_{2}$ quartz sensor (a) before PBS buffer treatment, (b) after PBS buffer treatment and (c) after QCMD experiment with FITC-BSA protein solution over a period 

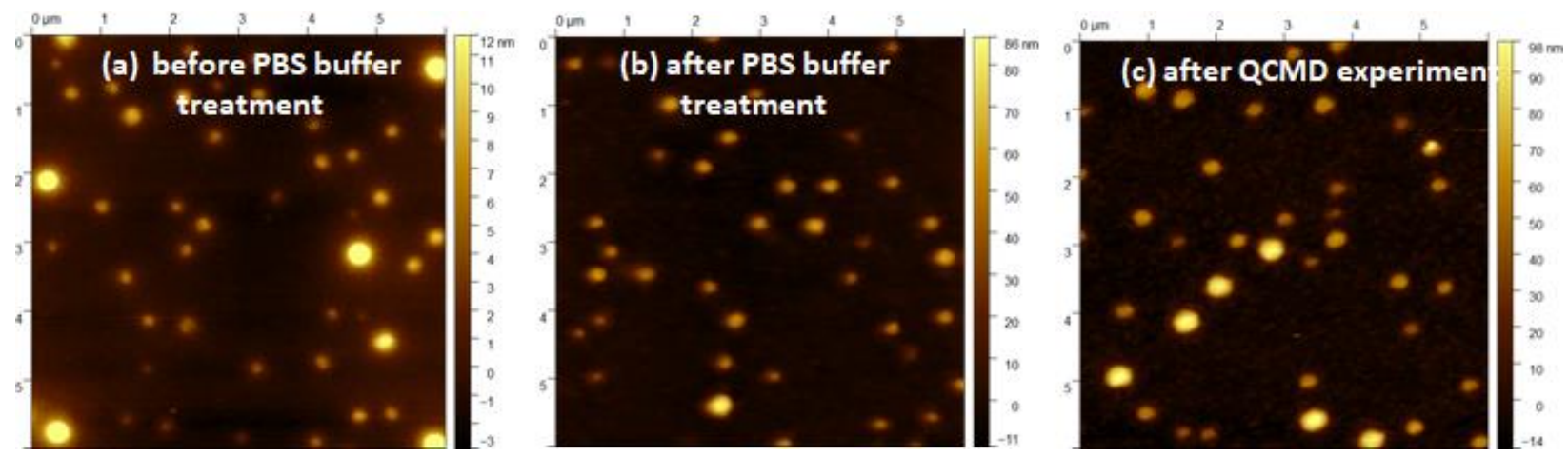

Figure S 19. AFM images of pure PVCL microgel coated on $\mathrm{SiO}_{2}$ quartz sensor (a) before PBS buffer treatment, (b) after PBS buffer treatment and (c) after QCMD experiment with FITC-BSA protein solution over a period

(A)
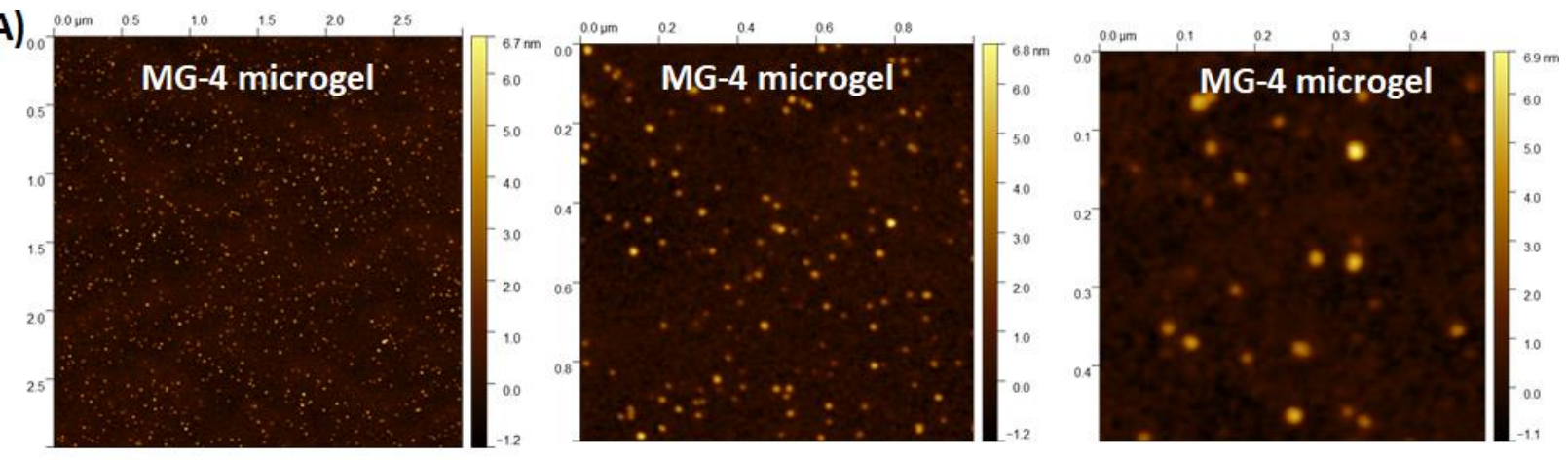

(B)
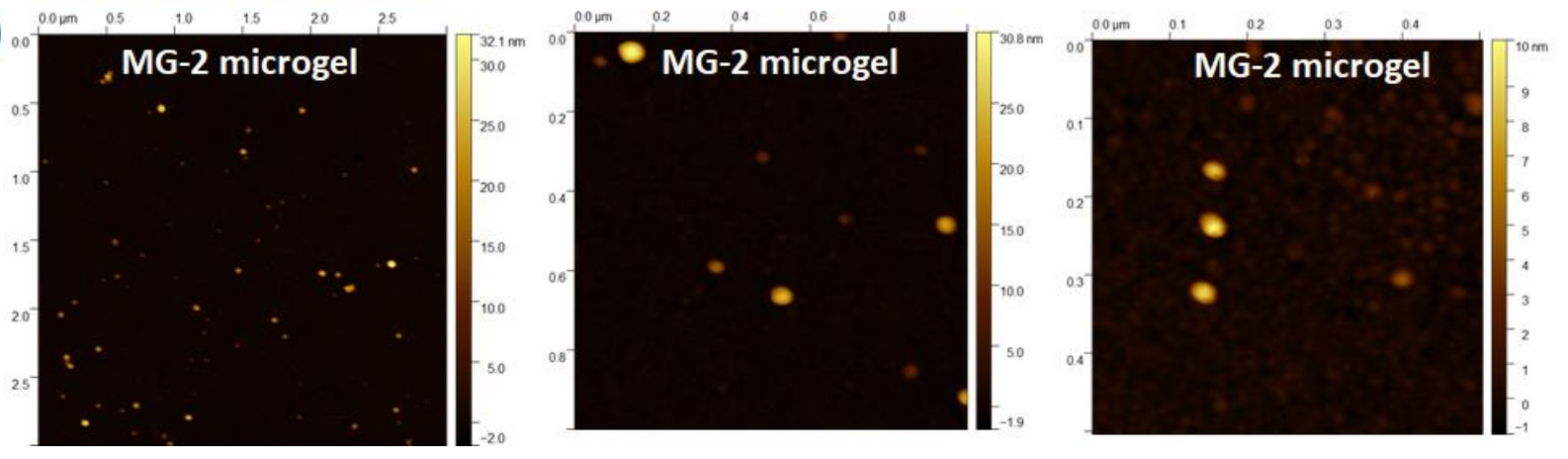

Figure S 20. AFM images of (A) MG-4 (top) and (B) MG-2 (bottom) microgels at different dimensions; left images: $3 \times 3 \mu \mathrm{m}$, central images: $1 \mathrm{x} 1 \mu \mathrm{m}$ and right images: $0.5 \times 0.5 \mu \mathrm{m}$ 